\title{
A PERCEPÇÃO DOCENTE SOBRE ATUAÇÃO DO TÉCNICO EM ASSUNTOS EDUCACIONAIS DE EDUCAÇÃO FÍSICA DE UMA UNIVERSIDADE PÚBLICA NO CONTEXTO DA FORMAÇÃO PROFISSIONAL
}

\author{
THE PROFESSOR' PERCEPTION ON PERFORMANCE OF \\ PHYSICAL EDUCATION TECHNICIAN IN EDUCATIONAL \\ SUBJECTS IN THE PUBLIC UNIVERSITY OF THE \\ PROFESSIONAL TRAINING CONTEXT
}

\begin{abstract}
LA PERCEPCIÓN DOCENTE SOBRE EL DESENVOLVIMIENTO DEL TÉCNICO EN ASUNTOS EDUCACIONALES DE EDUCACIÓN FÍSICA DE UNA UNIVERSIDAD PÚBLICA EN EL CONTEXTO DE LA FORMACIÓN PROFESIONAL
\end{abstract}

Carlos Fernando Barreto de Oliveira ${ }^{\mathrm{I}}$

${ }^{\text {I }}$ Universidade Federal de São Paulo (UNIFESP), Santos/SP -Brasil Rogério CRUZ DE OlIVEIRA ${ }^{\text {II }}$

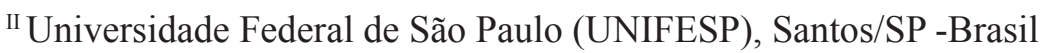

ReSumo O objetivo do estudo foi o de compreender a percepção docente sobre a atuação do Técnico em Assuntos Educacionais de Educação Física de uma universidade pública no contexto da formação profissional. Para tanto, foi desenvolvida uma pesquisa descritiva que contou com a participação de dez docentes do curso de Educação Física da UNIFESP - Campus Baixada Santista. A entrevista semiestruturada foi utilizada como instrumento de coleta de dados, a qual problematizou: a) Em sua opinião, o Técnico em Assuntos Educacionais de Educação Física tem participação na formação dos alunos do curso de Educação Física? e; b) Quais possibilidades você enxerga para a atuação do Técnico em Assuntos Educacionais de Educação Física na formação dos alunos do curso Educação Física? A análise dos dados foi feita por categorias não apriorísticas. Os resultados apontaram que os professores compreendem de forma distinta a atribuição dos Técnicos em Assuntos Educacionais, refletindo a abrangência da legislação a respeito do cargo. Conclui-se que os docentes não possuem clareza da natureza da atribuição dos Técnicos em Assuntos Educacionais.

Palavras-chave: Educação em Saúde; Educação Física; Educação Superior; FormaÇão de Recursos Humanos; Prática Profissional. 
ABSTRACT This study aimed at comprehending of the professor' perception on performance of Physical Education Technician in Educational Subjects in the public university of the professional training context. For that, a descriptive research was developed and counted on the participation of ten teachers of the Physical Education course of the UNIFESP - Campus Baixada Santista. The semi-structured interview was used for data collection, and it addressed two questions: a) In your opinion, have Physical Education Technician in Education Subjects ever participated from professional training of physical education'students? and; b) Can you see possibilities to Physical Education Technician in Educational Subject's performance in a professional training of physical education' students? If you see, which ones? The data analysis was performed by non-a priori categories. Results showed that teachers understand in a different way the assignment of the Technicians in Educational Subjects reflecting the scope of legislation on the position. We concluded that the professors cannot clarity on the Physical Education Technicians in Educational Subjects' professional practices.

Keywords: Health Education; Physical Education and Training; Higher Education; Staff Development; Professional Practice.

Resumen El objetivo del estudio fue el de comprender la percepción docente sobre el desenvolvimiento del Técnico en Asuntos Educacionales de Educación Física de una universidad pública en el contexto de la formación profesional. Por lo tanto, fue desarrollada una investigación descriptiva que contó con la participación de diez docentes del curso de Educación Física de la UNIFESP - Campus Baixada Santista. La entrevista semiestructurada fue utilizada como instrumento para recolectar datos, la cual problematizó: a) ¿En su opinión, el Técnico en Asuntos Educacionales de Educación Física tiene participación en la formación de los alumnos del curso de Educación Física? y b) ¿Que posibilidades observas para el desarrollo del Técnico en Asuntos Educacionales de Educación Física en la formación de los alumnos del curso de Educación Física? El análisis de los datos fueron hechas por categorías no aprioristicas. Los resultados apuntaron que los profesores comprenden de forma distinta la atribución de los Técnicos en Asuntos Educacionales reflexionando el alcance de la legislación sobre el cargo. Concluyendo que los docentes no poseen claridad en la especificación de la atribución de los Técnicos en Asuntos Educacionales.

Palabras Clave: Educación en la salud; Educación Física; Educación Superior; Formación de Recursos Humanos; Práctica Professional.

\section{INTRODUÇÃo}

O Técnico em Assuntos Educacionais (TAE) é um profissional de nível superior atuante nas Instituições Federais de Ensino (IFES) com provimento mediante concurso público. Embora o cargo seja estruturado pela Lei 11.091/2005, esta não reza sobre as atribuições específicas do TAE, apenas as atribuições da carreira de forma geral, a saber: 
I - planejar, organizar, executar ou avaliar as atividades inerentes ao apoio técnico-administrativo ao ensino;

II - planejar, organizar, executar ou avaliar as atividades técnico-administrativas inerentes à pesquisa e à extensão nas Instituições Federais de Ensino;

III - executar tarefas específicas, utilizando-se de recursos materiais, financeiros e outros de que a Instituição Federal de Ensino disponha, a fim de assegurar a eficiência, a eficácia e a efetividade das atividades de ensino, pesquisa e extensão das Instituições Federais de Ensino.

$\S 1$ o As atribuições gerais referidas neste artigo serão exercidas de acordo com o ambiente organizacional.

$\S 2$ - As atribuições específicas de cada cargo serão detalhadas em regulamento (BRASIL, 2005b, p. 2, Artigo 8)

No que se refere à regulamentação específica, o Ofício Circular no. 15/2005 descreve que a carreira de TAE exige a formação em pedagogia ou licenciaturas e possui a seguinte natureza:

DESCRIÇÃO SUMÁRIA DO CARGO:

Coordenar as atividades de ensino, planejamento e orientação, supervisionando e avaliando estas atividades, para assegurar a regularidade do desenvolvimento do processo educativo. Assessorar nas atividades de ensino, pesquisa e extensão. DESCRIÇÃO DE ATIVIDADES TÍPICAS DO CARGO

- Planejar, supervisionar, analisar e reformular o processo de ensino aprendizagem, traçando metas, estabelecendo normas, orientando e supervisionando o cumprimento do mesmo e criando ou modificando processos educativos em estreita articulação com os demais componentes do sistema educacional, para proporcionar educação integral aos alunos.

- Elaborar projetos de extensão.

- Realizar trabalhos estatísticos específicos.

- Elaborar apostilas.

- Orientar pesquisas acadêmicas.

- Utilizar recursos de informática.

- Executar outras tarefas de mesma natureza e nível de complexidade associadas ao ambiente organizacional. (BRASIL, 2005a, p. 50)

No entanto, mesmo com tal descrição, Pio (2012) e Sanseverino e Gomes Júnior (2014) afirmam haver uma dificuldade em situar as atribuições de acordo com a legislação. Se no âmbito geral esse é o panorama, no âmbito específico de um cargo de TAE com exigência em licenciatura em educação física (TAE/EF), isso parece não ter diferença.

\section{O TAE/EF E SUA ESPECIFICIDADE}

Se observados os editais de concurso público das IFES do Estado de São Paulo entre 2004 e 2014, o certame para TAE/EF ocorreu em duas oportunidades: um na Universidade Federal de São Paulo - Campus Baixada Santista (UNIFESP-BS, 2008) e o outro na Universidade Federal do ABC (UFABC, 2013).

No concurso da UNIFESP-BS (2008), regido pelo Edital 454, a descrição sumária das atividades possuía a seguinte redação: 
Ensinar os princípios e regras técnicas de atividades desportivas, orientação ética dessas atividades; desenvolver com estudantes e pessoas interessadas as práticas de ginásticas, exercícios físicos e ensinar-lhes as técnicas de jogos simples; treinar atletas nas técnicas de diversos jogos e outros esportes; instruir os atletas sobre os princípios éticos e regras inerentes a cada um deles; acompanhar e supervisionar as práticas desportivas; executar outras tarefas de mesma natureza ou nível de complexidade associado à sua especialidade ou ambiente. Assessorar nas atividades de ensino, pesquisa e extensão.

Já no concurso da UFABC (2013), regido pelo Edital 91, a descrição apareceu dividida em "Descrição sumária do cargo" e "Descrição de atividades típicas do cargo", a saber:

Descrição sumária do cargo: Coordenar as atividades de ensino, planejamento, orientação, supervisionando e avaliando estas atividades, para assegurar a regularidade do desenvolvimento do processo educativo. Assessorar nas atividades de ensino, pesquisa e extensão. Descrição de atividades típicas do cargo: Planejar, supervisionar, analisar e reformular o processo de ensino aprendizagem, traçando metas, estabelecendo normas, orientando e supervisionando o cumprimento do mesmo e criando ou modificando processos educativos de estreita articulação com os demais componentes do sistema educacional para proporcionar educação integral dos alunos. Elaborar projetos de extensão. Realizar trabalhos estatísticos específicos. Elaborar apostilas. Orientar pesquisas acadêmicas. Utilizar recursos de Informática. Executar outras tarefas de mesma natureza e nível de complexidade associadas ao ambiente organizacional. Planejar e desenvolver atividades na área de esporte e lazer. Acompanhar e supervisionar as práticas desportivas. Ensinar os princípios pedagógicos, técnicos e regras de esportes, ginástica, jogos, lutas e atividades rítmicas expressivas. Orientar o treinamento físico-esportivo nas diversas modalidades esportivas, baseados em princípios pedagógicos e técnico-científicos. Acompanhar e supervisionar a gestão das práticas desportivas e elaborar propostas de políticas públicas para o esporte e lazer universitários. Utilizar recursos da tecnologia da informação e da comunicação de forma a ampliar e diversificar as formas de interagir com as fontes de produção e de difusão de conhecimentos específicos da Educação Física e de áreas afins (UFABC, 2013, p. 29-30, grifos no original).

Embora a especificidade nos dois editais culmine em ações próprias do campo da Educação Física, em ambos os casos se nota uma grande abrangência na atribuição e nas atividades dos TAE/EF. No que se refere à lotação, existe uma distinção ímpar. Enquanto o TAE/EF no contexto da UFABC é lotado na Seção de Esportes e Lazer da instituição, vinculado à Coordenadoria de Assuntos Comunitários da instituição, o TAE/EF da UNIFESP-BS está ligado ao curso de Bacharelado em Educação Física. ${ }^{1}$ Ou seja, temos o cargo de TAE/EF em duas IFES em contextos distintos e com funções abrangentes, o que alimenta o quadro problemático da função.

Nesse sentido, faz-se necessário aprofundar o olhar sobre o TAE/EF nas IFES, objetivando compreender sua função educacional no ensino superior, haja vista a grande abran-

1 O curso de Educação Física da UNIFESP-BS só proporciona a modalidade de Bacharelado, diferente de outras instituições públicas que oferecem ainda a modalidade de Licenciatura. 
gência na descrição de suas atividades. Para este trabalho, a ótica docente acerca da atuação do TAE/EF foi priorizada. Foi realizada uma leitura da situação atual e das possibilidades de trabalho desse profissional. Para tanto, foram feitos os seguintes questionamentos: a) Em sua opinião, o Técnico em Assuntos Educacionais de Educação Física tem participação na formação dos alunos do curso de Educação Física? e; b) Quais possibilidades você enxerga para a atuação do Técnico em Assuntos Educacionais de Educação Física na formação dos alunos do curso Educação Física?

\section{A FORMaÇão EM EduCaÇão FísICA Na UNIFESP-BS}

Este estudo volta atenção para o TAE/EF no âmbito da formação inicial em Educação Física, tendo a UUNIFESP-BS como objeto de estudo. A escolha dessa instituição deveu-se, segundo Oliveira e Andrade (2016) e Fonseca, Menezes, Feitosa e Loch (2012), ao inovador Projeto Pedagógico de Curso de Educação Física (UNIFESP-BS, 2016), que tem ofertado uma formação interdisciplinar e interprofissional em saúde conjugado com outros cinco cursos.

A formação acontece com as áreas de Fisioterapia, Terapia Ocupacional, Nutrição, Psicologia e Serviço Social. Assim, os cursos são organizados em quatro eixos temáticos, dos quais três são comuns aos seis cursos e um é específico à formação em Educação Física. Os eixos comuns possuem a organização em eixos temáticos desenvolvidos por meio de módulos interdisciplinares, os quais são incluídos em turmas mistas, obedecendo ao pressuposto interprofissional. Segundo o PPCEF, os eixos comuns são:

- O Ser Humano e sua Inserção social;

- Trabalho em Saúde;

- O Ser Humano em sua Dimensão Biológica.

- O eixo específico é denominado Aproximação a uma Prática Específica de Educação Física e possui divisões em subeixos, visando uma melhor organização, conforme descrito em UNIFESP-BS (2016):

- Aproximação à prática da Educação Física e Saúde;

- Fundamentos das Atividades Físicas e Esportivas;

- Produção de conhecimento em Educação Física e Saúde;

- Ciências do Exercício Físico;

- Estudo do Movimento Humano;

- Ciências aplicadas à Educação Física;

- Tópicos em Educação Física e Saúde.

Em termos gerais, os objetivos do ensino de graduação da instituição estão calcados na formação de um profissional da área de saúde preparado para o trabalho em equipe e para a integralidade do cuidado, nos âmbitos técnico-científico, científico e humanístico (UNIFESP-BS, 2016).

Nessa mesma perspectiva, o curso de Educação Física tem como objetivo a formação de um bacharel capaz de

[...] diagnosticar, planejar, prescrever, orientar, assessorar, supervisionar, controlar e avaliar projetos e programas de atividades físicas, de exercícios físicos, atividades recreativas e esportivas nas perspectivas da prevenção, promoção, proteção e reabilitação da saúde [...] (UNIFESP-BS, 2016, p. 47, grifos no original). 
Além disso, na leitura do PPCEF fica evidente a ênfase na formação pautada na pesquisa, na produção de conhecimento e no exercício profissional voltado para a área de saúde, sem, no entanto, caracterizá-la como uma habilitação ou especialização precoce, e sim como um núcleo de aprofundamento temático.

Frente a esse contexto inovador e desafiador da formação profissional em Educação Física aliado à problemática da abrangência de atuação do TAE/EF nas IFES, o objetivo do estudo consiste em:

- Compreender a percepção ${ }^{2}$ docente sobre a atuação do Técnico em Assuntos Educacionais de Educação Física de uma universidade pública no contexto da formação profissional.

Trata-se de um recorte de uma dissertação de mestrado defendida em 2015 que, além desse objetivo, buscou compreender a ótica do próprio TAEF/EF da UNIFESP-BS nesse processo. Entretanto, por limites impostos a um texto como esse não foi possível abordar tal dimensão neste texto.

\section{MÉTOdo}

Para fins deste estudo foi desenvolvida uma pesquisa descritiva que, segundo Triviños (2008, p. 110), possui foco essencial no conhecer, bem como “[...] descrever com 'exatidão' os fatos e fenômenos de determinada realidade". No caso deste estudo, os fatos e fenômenos da ótica docente sobre a atuação dos TAE's na formação inicial dos alunos num curso de Educação Física.

A abordagem do estudo é de natureza qualitativa, que, segundo Minayo (1994), responde a questões muito particulares, preocupando-se com um nível de realidade que não pode ser quantificado. "Ou seja, ela trabalha com o universo de significados, motivos, aspirações, crenças, valores e atitudes, o que corresponde a um espaço mais profundo de relações, dos processos e fenômenos que não podem ser reduzidos à operacionalização de variáveis" (MINAYO, 1994, p. 22).

Os voluntários do estudo consistiram em dez docentes, que foram selecionados a partir dos seguintes critérios de inclusão:

- $\quad$ Ser docente do curso de Educação Física da UNIFESP-BS;

- Possuir jornada de trabalho de, no mínimo, 40 horas semanais;

O critério de não inclusão consistiu em:

- Ter menos que dois anos de exercício na função docente na instituição.

Como instrumento de coleta de dados foi utilizada a entrevista semiestruturada, que, para Triviños (2008, p. 146), é “[...] aquela que parte de certos questionamentos básicos, apoiados em teorias e hipótese, que interessam à pesquisa, e que, em seguida, oferecem amplo campo de interrogativas [...]". De acordo com o autor, ao mesmo tempo em que essa técnica valoriza a presença do investigador, oferta ainda o contexto necessário para que o voluntário se sinta livre em suas respostas, o que enriquece o processo de investigação. No caso deste estudo, o roteiro de entrevista esteve norteado por duas questões: a) Em sua opinião, o Técnico em Assuntos Educacionais de Educação Física tem participação na formação dos alunos do curso de Educação Física? e; b) Quais possibilidades você enxerga para a atuação

2 Na direção de Abbagnano (2007), a construção do significado. 
do Técnico em Assuntos Educacionais de Educação Física na formação dos alunos do curso Educação Física? Embora semelhantes, essas duas questões possuíram diferentes finalidades: o intuito com a primeira questão foi o de retratar o presente da instituição quanto à atuação do TAE/EF no contexto formativo dos alunos de graduação, ao passo que a segunda questão buscou cercar um cenário possível (ideal e futuro). Também foram coletados dados dos voluntários acerca da formação acadêmica e a experiência docente na instituição pesquisada.

Os voluntários foram convidados a participar da pesquisa por meio de e-mail ou pessoalmente, na própria instituição. As entrevistas ocorreram numa sala reservada, de modo a garantir um ambiente favorável ao diálogo sem interrupções de terceiros. Todos os voluntários assinaram um Termo de Consentimento Livre e Esclarecido e o estudo foi aprovado pelo Comitê de Ética e Pesquisa da instituição. As entrevistas foram realizadas entre setembro e novembro de 2014.

A análise de dados foi feita por meio de categorias não-apriorísticas, que, de acordo com Campos (2004, p. 614), "[...] emergem totalmente do contexto das respostas dos sujeitos da pesquisa, o que inicialmente exige do pesquisador um intenso ir e vir ao material analisado [...]". Seguindo os pressupostos do autor, a elaboração das categorias foi feita por "[...] freqüenciamento ou quase-quantitativa (repetição de conteúdos comuns à maioria dos respondentes) ou por relevância implícita (tema importante que não se repete no relato dos outros respondentes, mas que guarda em si, riqueza e relevância para o estudo" (p. 614, grifos no original).

\section{RESULTADOS E DISCUSSÃo}

Em relação ao perfil dos voluntários (Quadro 1), percebe-se que, com exceção da Professora 2, eles iniciaram o exercício do magistério superior na própria instituição, todos os/as outros/as possuíam experiência prévia anterior à UNIFESP-BS.

Quadro 1 - Perfil dos voluntários

\begin{tabular}{|c|c|c|}
\hline IDENTIFICAÇÃ̃O $^{1}$ & $\begin{array}{l}\text { TEMPO DE ATUAÇÃO NO } \\
\text { MAGISTÉRIO SUPERIOR }\end{array}$ & $\begin{array}{l}\text { TEMPO DE ATUAÇÃO NO } \\
\text { MAGISTÉRIO SUPERIOR NA } \\
\text { UNIFESP }\end{array}$ \\
\hline Professor 1 & 9 anos & 3 anos \\
\hline Professora 2 & 8 anos & 8 anos \\
\hline Professor 3 & 20 anos & 6 anos \\
\hline Professora 4 & 6 anos & 5 anos \\
\hline Professor 5 & 7 anos & 5 anos \\
\hline Professor 6 & 9 anos & 6 anos \\
\hline Professor 7 & 10 anos & 7 anos \\
\hline Professor 8 & 9 anos & 9 anos \\
\hline Professor 9 & 10 anos & 3 anos \\
\hline Professor 10 & 11 anos & 4 anos \\
\hline
\end{tabular}

Fonte: dados da pesquisa.

${ }^{1}$ A identificação por números foi adotada para preservar o anonimato dos/as voluntários/as. 
Antes de iniciar o processo analítico é importante ressaltar que, durante as entrevistas, os professores se remeteram ao que eles vivenciaram em outras instituições, inclusive como alunos. Isso reforça a importância de entender os significados que cada professor constrói acerca do cargo de TAE/EF. Assim, o que será exposto nesta seção não é fruto apenas da sua experiência na UNIFESP, mas sim de toda a vida acadêmica.

Em relação à primeira pergunta da entrevista: - "Em sua opinião, o TAE/EF tem participação na formação dos alunos do curso de Educação Física?" - chegamos ao seguinte quadro analítico, a saber:

- Cinco professores responderam que o TAE/EF contribui com a formação do aluno;

- Três professores responderam que o TAE/EF não contribui com a formação dos alunos, e;

- Dois professores não souberam responder justificando desconhecimento da natureza do cargo.

Entre o conjunto das respostas afirmativas chegamos a três categorias analíticas que demonstram que, para os professores, os TAE/EF contribuem para a formação do aluno quando envolvidos nas atividades de:

1. Apoio pedagógico;

2. Administração;

3. Extensão e pesquisa;

Na categoria de "Apoio pedagógico", houve compreensão por parte de dois professores que a organização do ambiente da aula é parte importante da formação, uma vez que: "Se preciso de material para aula, quem me ajuda é o TAE/EF, se eu preciso de um som, disso ou daquilo, então o TAE/EF colabora muito" (Professora 2). Para o professor 8: “[...] a organização de aulas, o preparo dos cenários, ela tem um diferencial a partir que esse sujeito que ocupa a função técnica tem o olhar da área". Aqui, é válido ressaltar que existem outras visões sobre esse ponto, pois o professor 1, que respondeu negativamente à questão, não vê relação entre a atuação do TAE/EF e a formação dos alunos justamente por se tratar de apoio pedagógico. "Então vocês arrumam um espaço, tem tudo certo, vocês ficam com controle sobre tudo que está acontecendo" (Professor 1). Tal fato nos permite reafirmar que existe dificuldade em se saber os limites da atribuição do TAE/EF no contexto geral do ensino superior e na UNIFESP especificamente.

No que se refere à categoria "Administração", os professores afirmaram: "Você ajuda na parte administrativa, nas coisas que eu não consigo fazer” (Professora 2).

[...] colocando uma situação específica nossa, do espaço físico, eu não consigo enxergar hoje sem a função que o TAE/EF exerce lá, porque ficamos órfãos, por uma série de aspectos. O TAE/EF estando lá no dia a dia, só isso, só esse aspecto é uma influência importante na formação dos alunos (Professor 3).

Embora a professora 2 tenha ficado mais no plano geral, é possível compreender sua resposta no mesmo horizonte do professor 3 devido à natureza comum de serem responsáveis por módulos que utilizavam instalações esportivas (quadra e piscina) para o desenvolvimento de atividades, o que significa dizer que as atribuições dos TAE/EF, nesse cenário, extrapolavam o apoio pedagógico, indo ao encontro da gestão de horários, limpeza, manutenção do espaço e material, entre outros. 
Quanto à terceira categoria "Extensão e pesquisa", os professores 6 e 7 compreendem haver contribuição dos TAE/EF nas ações de: "Supervisão de ações de pesquisa [...]" (Professor 6). "[...] algumas possibilidades de captar recursos, de orientar, de estar presentes nos projetos [...] vocês têm condição de contribuir [...]" (Professor 7).

Nesse interim, podemos compreender que o conjunto das respostas afirmativas agrupadas nas categorias "Apoio pedagógico", "Administração" e "Extensão e pesquisa" denota que o TAE/EF, mesmo não protagonista das ações de formação, possui algo a contribuir, algo a acrescentar.

Em relação à segunda questão "Quais possibilidades você enxerga para a atuação do Técnico em Assuntos Educacionais de Educação Física na formação dos alunos do curso Educação Física?", a resposta dos professores pôde ser agrupada novamente em três categorias, a saber:

1. Apoio pedagógico

2. Ensino de graduação

3. Extensão e pesquisa

No que se refere à categoria "Apoio pedagógico", foi possível observar pela resposta de cinco professores que a ideia do TAE/EF numa função auxiliar ao docente nas atividades de graduação é valorizada com íntima relação à análise da mesma categoria da primeira questão. "[...] a ajuda de do TAE/EF é mais no sentido de material, de organizar essas coisas, não tanto diretamente na aula" (Professora 4). Para o professor 8, “[...] organização do ambiente, que é um nível que a gente já tem hoje. Então a organização de material, o preparo de um cenário esportivo [...]. Já de acordo com professor 9, o TAE/EF:

[...] poderia atuar de maneira mais efetiva é, por exemplo, nesse sentido que o técnico de laboratório faz [...] mostrar para as pessoas o que é um ambiente laboratorial, como a pessoa tem que se comportar lá dentro [...] então acho que essa é uma primeira colaboração. Um segundo momento, talvez num longo prazo [...] o TAE/EF acompanhar os professores para entender realmente o que eles falam, o que eles precisam para que o TAE/EF possa dar um suporte posterior para esses alunos no dia a dia para todas as disciplinas [...] Mas não é dar aula, é estar junto colaborando" [...].

O professor 3 já compreende que “[...] é na questão do dia a dia dos módulos [...] na parte que seria semelhante a uma monitoria, alguma coisa assim. Essa parte do dia a dia de aula, de avaliação, essa parte, com algumas ações isoladas”. Por fim, o professor 7 entende que o TAE-EF pode atuar como "[...] o braço direito imediato do docente a que ele está mais ligado".

Após o exposto, podemos perceber que, embora o apoio pedagógico tenha surgido como categoria analítica das duas questões do estudo, as respostas vieram de outros professores. A exceção foi o professor 8, que manteve o entendimento da função do TAE/ EF como apoio pedagógico nas duas questões. Em nosso entendimento, isso foi possível devido às diferentes finalidades das duas questões propostas no estudo, como já explicitado no método.

Já em relação à categoria "Ensino de graduação" foi possível observar no discurso de três professores que o TAE/EF pode desenvolver atividades com o professor em sala de 
aula, não o substituindo nem o apoiando, mas enriquecendo o contexto de formação. "O TAE/EF tem possibilidade de atuação, não só em situações práticas, mas atuação também em contextos teóricos na sala de aula" (Professora 2).

[...] eu acho que os TAE/EF poderiam ajudar mais na própria atividade em sala de aula [...]. Bastaria uma organização melhor, ter um cronograma das atividades e combinar com os TAE/EF no que poderiam ajudar [...] não só na parte dos materiais, mas em sala de aula e estar diretamente com os alunos em algumas atividades (Professora 4).

O espaço onde o curso pode construir é um espaço de crescimento, onde o TAE/EF vai contribuir com determinadas práticas, o docente vai contribuir com determinadas práticas e o estudante, nesse miolo, vai se construir. O que dá para ser feito entre eles? Dá para ser feito ações pedagógicas, trocas de ações pedagógicas, elaboração de programas de desenvolvimento [...] (Professor 6).

A principal observação a ser feita nessa categoria é a contradição da resposta da professora 4 quanto à natureza das atividades do TAE/EF na graduação. De acordo com a professora, ao mesmo tempo em que o TAE/EF pode estar diretamente envolvido com o aluno (resposta da questão 2) há também a clara afirmação - exposta na categoria anterior - de que a atuação é reduzida ao apoio pedagógico. Essa contradição pode ser compreendida pela dificuldade que os professores tiveram em dialogar com as questões propostas. Em nosso entendimento, trata-se de questões um tanto quanto desafiadoras, uma vez que a tradição institucional acadêmica parece já entender a natureza da atuação do técnico distante da formação dos alunos. Nesse sentido, compreendemos que as questões empreendidas pelo estudo fomentaram um momento inicial de reflexão para alguns professores, que, se tivessem tido outra oportunidade para dialogar sobre o tema ou ter se alongado na resposta, poderiam ter chegado a outras conclusões, como a professora 4 . Entretanto, também se observou que tanto a professora 2 quanto o professor 6 acreditam num cenário futuro/ideal de atuação do TAE/EF distinto do momento atual, que, respectivamente, entendem-na como apoio pedagógico e atividades de pesquisa e extensão.

Em relação à última categoria "Extensão e pesquisa", três professores compreenderam que as possibilidades de atuação do TAE/EF quanto à formação dos alunos se davam com a participação, acompanhamento e coordenação de projetos de extensão e pesquisa. "Em projetos de extensão conjuntos, que o curso possa desenvolver, e até mesmo projetos de pesquisa que eu acho que é fundamental [...]" (Professor 1).

[...] visualizo a possibilidade de estar à frente de uma ação, por exemplo, de extensão [...] eu vejo que os TAE/EF, graduados em educação física, também podem colaborar na organização desses projetos, na oferta desses projetos e na coordenação desses projetos [...] [e também no] acompanhamento de propostas de treinamento, de projetos de pesquisa, seja de autoria dos docentes ou até mesmo do próprio TAE/EF (Professor 8).

[...] no meu entendimento, eu acho perfeitamente possível que, por exemplo, técnicos estão pensando trabalhar assuntos educacionais, e, para mim educação é socializar cultura, que pudessem trabalhar em diferentes instâncias, níveis e formas de socializar essa cultura acadêmica, científica, artística, filosófica que é produzida e compartilhada dentro da universidade (Professor 5). 
Embora essa mesma categoria analítica esteja presente na primeira questão, a exemplo do "Apoio pedagógico", destacam-se as possibilidades de coordenação de projetos por parte do TAE/EF. Ainda que isso seja possível na maior parte das instituições de ensino superior, inclusive na UNIFESP, não é comum o corpo técnico coordenar projetos de extensão e pesquisa. Outro destaque gravita em torno da ampla resposta do professor 5, o qual chama atenção para o termo "educação", presente no título do cargo do TAE/EF, e para sua concepção de socialização de cultura. Em que pese a amplitude da resposta, podemos compreendê-la na chave das atividades de extensão. O último destaque dessa categoria é o fato de terem sido outros professores que compreendem essa possibilidade. Na resposta à primeira questão, foram os professores 6 e 7 que responderam na direção da extensão e da pesquisa.

Em suma, a análise da segunda questão nos aponta que, majoritariamente, os professores percebem a relação entre a atuação do TAE/EF e a formação do aluno por meio das atividades ligadas à dimensão do ensino, estritamente, no desenvolvimento das aulas. Mesmo que as atividades de extensão e pesquisa estejam presentes no discurso de alguns professores como cenário ideal de atuação do TAE/EF, o ensino foi o mais valorizado. Curioso notar que, sendo o TAE/EF um profissional da categoria técnico-administrativo, era de se esperar que os professores apontassem as questões administrativas como possibilidade de atuação, o que não ocorreu. Isso nos permite inferir que, para os professores, as funções administrativas desenvolvidas pelo TAE/EF na instituição são menos importantes para a formação dos alunos do que o ensino, a extensão e a pesquisa, o que corrobora com Sanseverino e Gomes (2017a), estudo que apresentou os resultados de um plano de ação criado para o cargo de TAE na Universidade Federal Fluminense em Angra dos Reis (UFF). Neste estudo, os resultados relacionados à dimensão do ensino se aproximam do discurso dos professores sobre as potencialidades da atuação do TAE/EF no ensino de graduação, se estendendo ainda para a dimensão da extensão e pesquisa. Entretanto, sendo o ensino valorizado pelos professores nesse tripé universitário, nos cabe fazer reflexões a respeito da natureza da atuação do TAE/EF nos processos formativos dos alunos de graduação.

Partindo do pressuposto de que os processos educativos, inclusive os desenvolvidos na formação profissional superior, são compostos de algo mais do que processos metodológicos, podemos inferir que o apoio pedagógico realizado pelo TAE/EF é dotado de certo reducionismo na tarefa de educar ou de formar, implicando uma visão tecnicista que restringe a contribuição do TAE/EF na formação do aluno. Para Sanseverino e Gomes (2017b), que investigaram o cargo de TAE na Universidade Federal Fluminense, a instituição deveria aproveitar melhor a força de trabalho desses profissionais, haja vista que a natureza do cargo possibilita o exercício de atividades vinculadas a processos educativos.

No mesmo estudo, os autores revelaram que esses servidores compreendiam sua atribuição na área administrativa, seguida pela administrativa-pedagógica, sendo que nenhum servidor considerou que as tarefas eram de natureza somente pedagógica. Mesmo não sendo um estudo específico sobre $\mathrm{TAE} / \mathrm{EF}$, os resultados nos levam a compreender outra direção da atribuição do cargo - o distanciamento das ações educacionais, fato esse que corrobora com nossos achados relativos à primeira questão, na qual três professores não compreendiam a contribuição do TAE/EF na formação dos alunos.

Nesse interim, Gonçalves, Abensur e Queiroz (2009), que estudaram a identidade do corpo técnico especialista em educação da rede federal de educação profissional, científica e 
tecnológica, afirmam que a inclusão desses especialistas na carreira dos cargos técnico-administrativos traz prejuízo ao desenvolvimento de uma educação de qualidade, pois trata:

\begin{abstract}
[...] os problemas educacionais como meros problemas metodológicos e burocráticos [...] A dicotomia do trabalho pedagógico verificado na definição da Carreira do Magistério do Ensino Básico, Técnico e Tecnológico e da Carreira dos Técnico-Administrativos em Educação, quando incluídos os cargos de Pedagogos e TAE, faz-nos refletir sobre a verdadeira concepção que há na esfera federal em relação à educação profissional, que nesta perspectiva é a de treinamento, mecânico e sem reflexão, esquecendo-se, portanto, da formação total do ser humano (GONÇALVES, ABENSUR e QUEIROZ, 2009, p. 14).
\end{abstract}

Embora os autores se remetam à outra esfera de formação que não a do ensino superior, a reflexão é pertinente com este estudo. A ideia de dicotomizar o ensino entre a esfera docente e a esfera técnica, por exemplo, acaba por empobrecer o currículo universitário e também a ação do técnico, pois dá a entender que o lugar desse técnico está no tratamento de atividades descoladas dos aspectos educacionais mais amplos.

Nesse cenário de compreensões tão distintas sobre o TAE/EF, por parte dos professores, compreendemos que há, de fato, uma dificuldade em conceber a atuação desse profissional no ensino superior. Assim, num terreno tão incerto, perspectivas extremas convivem lado a lado, como é o caso deste estudo e, também, como demonstram Sanseverino e Gomes Júnior (2014, p. 17) em seus achados:

\begin{abstract}
Apesar de a pesquisa não investigar a satisfação dos servidores no exercício do cargo, 04 Técnicos em Assuntos Educacionais demonstraram insatisfação em suas respostas, declarando sobre a indefinição do papel desse profissional, a falta de autonomia, a execução de tarefas meramente administrativas, o sentimento de desvalorização, a falta de motivação, a descrença no trabalho, dentre outros aspectos. Por outro lado, as sugestões de atividades pertinentes ao cargo revelaram o desejo de atuar na área pedagógica em parceria com as coordenações e direções das Unidades de Ensino, de auxiliar os alunos em seu processo de aprendizagem, de colaborar no desenvolvimento da universidade, de propor melhorias nos processos de trabalho etc.
\end{abstract}

Ou seja, a indefinição do cargo nas leis e no cotidiano universitário permite binarismos que podem conduzir a limitações e potencialidades. No nosso estudo, compreendemos que as limitações estão ligadas à ideia do TAE/EF com atribuição de apoio pedagógico e que as potencialidades têm íntima relação com o desenvolvimento de atividades de ensino de graduação, lado a lado com o professor, como apontado por três professores, bem como, a coordenação e desenvolvimento de atividades de extensão e pesquisa.

Na pista das potencialidades, é válido ressaltar a necessidade de ampliação do escopo do que se entende por processo educativo e de formação humana, que embora seja um conceito de largo espectro e de difícil consenso, permeia espaços, subjetividades, intersubjetividades, encontros e experiências.

Dominicé (2012) afirma que, de fato, há uma multiplicidade de significados atribuídos ao termo "formação", ressaltando, grosso modo, que este não se limita a um diploma, nem 
a um programa e nem a uma lei. A formação transcende a todas essas questões e se insere no sujeito que é fruto de determinada sociedade e sua cultura. Imbernón $(2005$, p. 30) auxilia nessa reflexão no que tange ao profissional de educação e sua relação com o conhecimento pedagógico: "O conhecimento pedagógico comum existe logicamente na estrutura social, integra o patrimônio cultural de uma sociedade determinada e se transfere para as concepções dos professores". Ou seja, toda formação de um sujeito, seja de qualquer natureza, não pode ser pensada senão nele mesmo, considerando suas subjetividades, para não incorrer no risco de ações fragmentadas e sem significados.

Nessa esteira, Dominicé (2012) aponta para três elementos-chave para o entendimento dessa questão. De acordo com o autor, o primeiro ponto está relacionado à completude do ser humano inscrito no percurso de vida com base nas suas aprendizagens, reconhecendo suas múltiplas facetas, por exemplo, vida familiar, profissional, cultural, esportiva etc. Já no segundo ponto, o autor afirma que se relaciona com as tensões pessoais, configurado nos atritos comuns entre polarizações, como a carreira profissional e origem social, tradições e sua confrontação com a multiplicidade de valores numa sociedade globalizada, podem ser enxergadas como exemplos. E, por fim, o conceito de bifurcação, que ocorre quando a formação muda de percurso devido a uma ruptura na vida pessoal, por exemplo, a morte de um ente querido, desemprego etc. (DOMINICÉ, 2012).

\footnotetext{
Estas três centralidades, que destaco para situar os processos que caracterizam a formação de adultos, representam uma tentativa de compreender melhor como os adultos se formam ou, mais exatamente, como a formação se constrói no curso da vida adulta. Do ponto de vista epistemológico, constato que as histórias de vida que analisei não separam as dimensões cognitivas e afetivas do desenvolvimento, não opõem o curso escolar e as aprendizagens informais, não dissociam as dimensões mentais, simbólicas ou psico-corporais. A vida é tomada como um todo (DOMINICÉ, 2012, p. 28).
}

Ou seja, a formação precisa se dar em amplo alcance, indo além da sala de aula e buscando superar os reducionismos existentes, principalmente aqueles oriundos de uma concepção de educação que destina ao TAE e TAE/EF a função burocrática ou administrativa.

\section{CONSIDERAÇões FINAIS}

Ao buscar compreender a percepção docente sobre a atuação do TAE/EF Técnico em Assuntos Educacionais de Educação Física da UNIFESP-BS no contexto da formação profissional, fomos imersos a uma gama de discursos que apontaram limites e possibilidades. Os limites gravitaram em torno da compreensão da atuação do TAE/EF como apoio pedagógico das atividades desenvolvidas nas aulas de graduação. Entretanto, surgiram possibilidades por meio do entendimento de que o TAE/EF pode desenvolver atividades com o docente na graduação, bem como, coordenar, desenvolver e acompanhar projetos de extensão e pesquisa.

Frente a esse cenário, foi possível compreender que a existência de percepções tão distintas se deve, ainda, a uma falta de clareza da natureza da atribuição do TAE, em geral 
e, no caso deste estudo, do TAE/EF nas IFES. Em nossa ótica, a definição das atribuições desses cargos colaboraria para dirimir as dificuldades de entendimentos e ações por parte do TAE, contribuindo para um cenário curricular mais amplo e aberto.

Nessa perspectiva, nos aliamos a Macedo (2013), para o qual o currículo no espaço educacional deve ser uma prática que englobe todos os atores educacionais. No caso deste estudo, uma prática que compreenda o TAE/EF como um ator que possui algo a contribuir na formação dos alunos. Nessa esteira, compreende-se o projeto político-pedagógico de qualquer instituição como um espaço favorável para a inserção das reflexões e apontamentos sobre as práticas pedagógicas em seu cunho mais abrangente, inclusive aquelas não oriundas do corpo docente.

\section{REFERÊNCIAS}

ABBAgnanAnO, N. Dicionário de Filosofia. São Paulo: Martins Fontes, 2007.

BRASIL. Lei no . 11.091, de 12 de janeiro de 2005. Dispõe sobre a estruturação do Plano de Carreira dos Cargos Técnico-Administrativos em Educação, no âmbito das Instituições Federais de Ensino vinculadas ao Ministério da Educação, e dá outras providências. Diário Oficial [da] República Federativa do Brasil, Brasília, Brasil, n. 9, p. 1-10, 13 jan. 2005a, Seção 1.

BRASIL. Ministério da Educação. Secretaria Executiva. Subsecretaria de Assuntos Administrativos. Coordenação Geral de Gestão de Pessoas. Encaminha a descrição dos cargos técnico-administrativos em educação, que foram autorizados pelo Ministério de Planejamento, Orçamento e Gestão para concurso público. Ofício Circular $\mathbf{n}^{\mathbf{0}} . \mathbf{0 1 5}$, de 28 de novembro de 2005 b.

CAMPOS, C. J. G. Método de análise de conteúdo: ferramenta para a análise de dados qualitativos no campo da saúde. Revista Brasileira de Enfermagem, Brasília, v. 57, n. 5, p. 611-614, out. 2004.

DOMINICÉ, P. A epistemologia da formação ou como pensar a formação. In: MACEDO, R. S. et al. (Orgs.). Currículo e processos formativos: Experiências, saberes e culturas. Salvador: EDUFBA, 2012, p. 9-38.

FONSECA, S.A. et al. Notas preliminares sobre a Associação Brasileira de Ensino da Educação Física para a saúde - Abenefs. Caderno Fnepas, Brasília, v. 2, s/n, p. 38-48, jan. 2012.

GONÇALVES, H. J. L.; ABENSUR, P. L. D.; QUEIROZ, S. M. Identidade de profissionais da educação na rede federal de educação profissional, científica e tecnológica: os especialistas em educação. Sinergia, São Paulo, v. 10, n. 1, p. 9-15, jan./jun. 2009. 
IMBERNÓN, F. Formação docente e profissional: Formar-se para a mudança e a incerteza, 5. ed. São Paulo: Cortez, 2005.

MACEDO, R. S. Atos de currículo e autonomia pedagógica: O socioconstrucionismo curricular em perspectiva. Petrópolis, Brasil: Vozes, 2013.

MINAYO, M. C. S. (Org.). Pesquisa social: Teoria, método e criatividade, 9. ed. Petrópolis: Vozes, 1994.

OLIVEIRA, R. C.; ANDRADE, D. R. Formação profissional em Educação Física para o setor da saúde e as Diretrizes Curriculares Nacionais. Pensar a Prática, Goiânia, v. 19, n. 4, p. 721-733, out./dez. 2016.

PIO, A. Técnico em Assuntos Educacionais do Colégio Pedro II: história, identidade e limites de atuação. Rio de Janeiro: UFRJ, 2012, 166s. Dissertação (Mestrado em Educação) - Faculdade de Educação. Universidade Federal do Rio de Janeiro, Rio de Janeiro, 2012.

SANSEVERINO, A. M.; GOMES, C. F. S. Plano de ação como estratégia para o cargo de técnico em assuntos educacionais. Revista Práticas em Gestão Pública Universitária, Rio de Janeiro, v. 1, n. 1, p. 35-56, mai. 2017a.

SANSEVERINO, A. M.; GOMES, C. F. S. Propostas dos técnicos em assuntos educacionais. Revista de Carreiras e Pessoas, São Paulo, v. 7, n. 2, p. 456-474, jan./ago. 2017 b.

SANSEVERINO, A. M.; GOMES JÚNIOR, S. F. O papel dos Técnicos em Assuntos Educacionais em uma Instituição Federal de Ensino Superior: atribuições e propostas de Ação. In: CONGRESSO NACIONAL DE EXCELÊNCIA EM GESTÃO, 10., 2014, Rio de Janeiro e Niterói. Anais... Rio de Janeiro e Niterói: Universidade Federal Fluminense, 2014, p. 1-21.

TRIVIÑOS, A. N. S. Introdução à pesquisa em ciências sociais: A pesquisa qualitativa em educação, 5. ed. São Paulo: Atlas, 2009.

UNIVERSIDADE FEDERAL DO ABC. Edital n. 91, 30 de julho de 2013.

UNIVERSIDADE FEDERAL DE SÃO PAULO. Edital no . 454, 8 de dezembro de 2008.

UNIVERSIDADE FEDERAL DE SÃO PAULO. Projeto pedagógico de curso: Bacharelado em educação física. Santos, 2016. 


\section{DADOS DOS AUTORES}

\section{Carlos Fernando Barreto de Oliveira}

Mestre em Ensino em Ciências da Saúde. Técnico em Assuntos Educacionais da Universidade Federal de São Paulo-Campus Baixada Santista. Santos/SP-Brasil. carlosfboliveira@, gmail.com.

\section{Rogério Cruz de Oliveira}

Doutor em Educação Física. Professor da Universidade Federal de São Paulo - Campus Baixada Santista. Santos/SP-Brasil.rogerio.cruz@unifesp.br.

Submetido em: 6-4-2020

Aceito em: 9-11-2020 